\title{
Spectrophotometric, thermal and determination of trace amount of palladium (II) nickel (II) and silver (I) by using pyrazolone azo derivative
}

\begin{abstract}
This study describes the use of novel azodyes reagents, $\mathrm{H}_{4} \mathrm{~L}, 1-[(1,5$-Dimethyl-3-oxo2-phenyl-2,3-dihydro-1 $H$-pyrazol-4-yl]-2,3,7,8-tetrahydroxychromeno(5,4,3-cde) chromene-5,10-dione, that prepare ellagic acid as a coupling agent with 4-aminoantipyrine, as sensitive and selective analytical reagent for the determination of palladium (II),nickel (II) and silver (I) Ions spectrophotometrically. $\mathrm{HL}$ reacts with ions at $\mathrm{pH}(3,8$ and 6$)$ respectively to form colored complexes of $1: 2$ stoichiometry of $\mathrm{Pd}(\mathrm{II}), \mathrm{Ni}(\mathrm{II})$ and $1: 1$ for $\mathrm{Ag}(\mathrm{I})$ which show a maximum absorbance of 504, 495 and $492 \mathrm{~nm}$ of molar ratio absorbitivity $3.565 \times 10^{3}, 1.966 \times 10^{3}$ and $4.735 \times 10^{3} \mathrm{~L} \mathrm{~mol}^{-1} \mathrm{~cm}^{-1}$ respectively. Fixed optimum conditions were constructed, precision, accuracy, R.S.D.andcorrelation factors. The Beers law was obeyed $0.1-3 \mathrm{ppm}$. The thermal measurements were also studied, all the complexes show three-stage mass loss in their TG/HDSC curves.
\end{abstract}

Keywords: spectrophotometric, azodyes, thermal analysis, palladium (II), nickel (II) and silver (I)
Volume 7 Issue 4 - 2018

\author{
Hussain J Mohammed,' Aayad Ammar \\ Syhood $^{2}$ \\ 'Department of Chemistry, University of Kufa, Najaf, Iraq \\ ${ }^{2}$ Department of Basic Sciences, University of Kufa, Najaf, Iraq
}

Correspondence: Hussain J Mohammed, Department of Chemistry, Faculty of Science, University of Kufa, Najaf, Iraq, Email Hussein.alshujairi@uokufa.edu.iq

Received: January 19, 2017 | Published: August 31, 2018

\section{Introduction}

Azo compounds are very important class of chemical compounds containing a hetro cyclic moiety which has attracted the attention of many researchers in the recent years. ${ }^{1}$ There has been increasing interest in syntheses of heterocyclic compounds that have biological and commercial importance clinical, ${ }^{2}$ and pharmacological activities. $^{3}$ One of the most important derivatives of antipyrine is 4-aminoantipyrine, which is used as a synthetic intermediate to prepare polyfunctionally substituted heterocyclic moieties. ${ }^{4}$

Azo compounds containing $\mathrm{N}_{3}$ donor atoms act as superior chelating agents for the transition and non-transition metal ions and showed biological activities. ${ }^{5}$ Azo days are commonly synthesized by coupling a diazonium reagent with an aromatic compound to form an azo reagent. ${ }^{6}$ The azo compounds give bright, high intensity colors, much more than the other most common compounds, in addition, they have fair to good fastness properties, their biggest advantage it their cost-effectiveness, which is due to the processes involved in manufacture. ${ }^{7}$ The coordinating property of 4-aminoantipyrine ligand has been modified to give a flexible ligand system, formed by condensation with variety reagents like aldehydes, ketones and carbazides. ${ }^{8}$

Ellagic acid, a dimeric derivative of gallic acid, is apolyphenolic antioxidant that occurs in its free form as aglycoside or is found as ellagitannins in fruits and nuts ofseveral plants. ${ }^{9}$ Several studies have reported the antioxidant, antimutagenic, anti-inflammatory and cardioprotective activityof ellagic acid. ${ }^{10}$ In this research, novel sensitive and selective azodyes was prepared by reaction 4-aminoantipyrine with ellagic acid as a coupling agent to determine trace amount of Pd (II), Ni (II) and $\mathrm{Ag}$ (I) as complexes.

\section{Experimental}

\section{Materials and methods}

All chemicals ofhighest purity were used in this work which supplied by Fluka and BDH. Spectrophotometric measurements were made with ShimadzuUV-Visible-1650Pc double beam. The FTIR measurements were made in Shimadz 8400 Series Japan. Differential Scanning Calorimeter DSC MODEL STA PT-1000 Linseis. Atomic Absorption Spectrophotometer Flame Model Shimadzu AA-7000F. Electricmolar conductivity measurements were carried out at room temperature usingan Alpha digital conductivity model-UK 9300. The $\mathrm{pH}$ measurements were performed with a "HANNA $\mathrm{pH}$ meter H19811-5 Instrument.

\section{Synthesis of $\mathbf{H}_{4} \mathrm{~L}$}

The reagents and solvents were of analytical grade and used without further purification. 4-Aminoantipyrine $(0.00492 \mathrm{~mole})$ $1.0000 \mathrm{gm}$ was diazotized by dissolving it in $25 \mathrm{ml}$ ethanol then $5 \mathrm{ml}$ of $\mathrm{HCl}$ was adding keeping the temperature at $0-5^{\circ} \mathrm{C}$ and then adding $\mathrm{NaNO}_{2}$ solution gradually and left the solution about $15 \mathrm{~min} .{ }^{11}$ The diazonium salt was spontaneously added slowly drop wise to a well cooled alkaline solution of coupling agent (ellagic acid $1.4869 \mathrm{gm}$ ), the mixture was allowed to stand for $1 \mathrm{~h}$. The dark colored mixture was neutralized with $\mathrm{HCl}$ and the solid precipitate was filtered off and washed several times with (1:1) (methanol: water) mixture then recrystallised from boiling methanol and left to dry (Scheme 1).

\section{Solutions}

A stock standard Palladium solution (100ppm) was prepared by dissolving $0.0353 \mathrm{~g}$ of $\mathrm{PdCl}_{2}$, the volume was completed to $200 \mathrm{ml}$ with distilled water. A stock standard Nickel solution (100ppm) was prepared by dissolving $0.0806 \mathrm{gm}$ of $\mathrm{NiCl}_{2} .6 \mathrm{H}_{2} \mathrm{O}$, the volume was completed to $200 \mathrm{ml}$ with distilled water. A stock standard Silver solution (100ppm) was prepared by dissolving $0.0314 \mathrm{gm}$ of $\mathrm{AgNO}_{3}$, the volume was completed to $200 \mathrm{ml}$ with distilled water. Solution of azodye reagent $\left(1 \times 10^{-3} \mathrm{M}\right)$ were prepared by dissolving $(0.0516 \mathrm{gm})$ and complete the volume to $100 \mathrm{ml}$ with absolute methanol. Foreign ions solutions $\left(100 \mu \mathrm{g} \mathrm{ml}^{-1}\right)$, these solutions were prepared by dissolving an amount of the compound in distilled water completing the volume in a volumetric flask. 


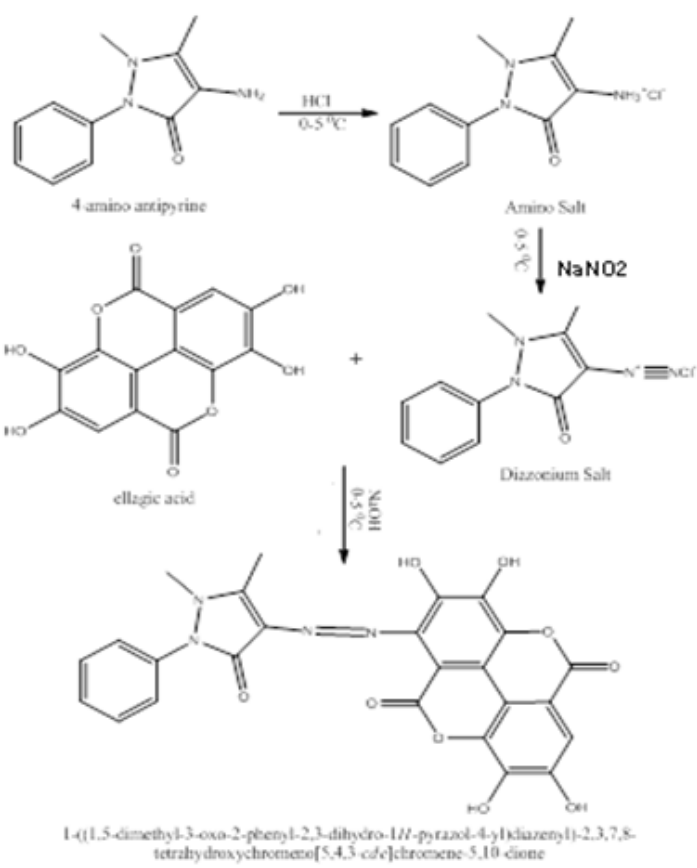

Scheme 1 Synthesis of $\mathrm{H}_{4} \mathrm{~L}$

\section{Procedure}

To get highest absorbance of complexes formed, it is necessary to get optimum conditions of forming each complex, which include, the selection of the suitable wavelength $\left(\lambda_{\max }\right)$, effect of time, effect of $\mathrm{pH}$ values, effect of sequence of additions, stoichiometry and effect of interferences of strange ions. The general procedure was summarized by taking $(0.1-3 \mathrm{ppm})$ of $\mathrm{Pd}(\mathrm{II}), \mathrm{Ni}(\mathrm{II})$ and $\mathrm{Ag}(\mathrm{I})$ ions with $(3 \mathrm{ml})$ of $1 \times 10^{-3} \mathrm{M}$ of $\mathrm{H}_{4} \mathrm{~L}$ then the volume was completed to $10 \mathrm{ml}$. After 15 min, the absorbance of formed complexes were measured at $\lambda_{\max }$ of 504,495 and $492 \mathrm{~nm}$ respectively.

\section{Results and discussion}

\section{Absorption spectra}

The electronic spectra of $\mathrm{H}_{4} \mathrm{~L}$ and their complexes with ions, $\operatorname{Pd}(\mathrm{II}), \mathrm{Ni}(\mathrm{II})$ and $\operatorname{Ag}(\mathrm{I})$. Complexes are at $\lambda_{\max }$ wavelengths were fixed in Figure 1, shows the absorbance $\lambda_{\max }$ at 504, 495 and $492 \mathrm{~nm}$ respectively. It is clear that according to the red shift that happened in $\lambda_{\max }$ show the stable complexes are formed immediately, $\pi \longrightarrow \pi^{*}$ transition within the azo group and heterocyclic moieties involving the whole $\pi$ electronic system of the compound influenced by intermolcular charge transfere character. ${ }^{12} \mathrm{~A}$ great bathochromic shift in the visible region was detected in the complex solution spectra with respect to that of the free ligand. The intensity colored solutions formed from the reaction of the azo ligands with the metal ions is playing an important rule for many UV-Vis spectral studies. This is because of the presence of a sharp and high absorption peak which belongs to the metal complex. The large bathochromic shift of this peak in the visible region with respect to that of the ligand may give a good indication on the complex formation.

\section{FTIR spectra}

The FT-IR data of $\mathrm{H}_{4} \mathrm{~L}$ reagent and their complexes are with their probable assignment given in Table 1. The important bands observed in the spectra of the complexes while comparing with reagents, which is helpful in detection of donation sites. The IR spectra of the free ligand have a broad band around $3415.9 \mathrm{~cm}^{-1}$ which could be attributed to $\mathrm{O}-\mathrm{H}$ stretching vibration and it shifted to lower frequency. The stretching frequency of carbonyl group of ligand $v(\mathrm{C}=\mathrm{O})$ 1676.14(s) $\mathrm{cm}^{-1}$ is shifted to a lower frequency in complexes. Similarly the frequency corresponding to $v(\mathrm{~N}=\mathrm{N})$ at $1494.8(s)$ is shifted to range (1383-1496) $\mathrm{cm}^{-1}$ in complexes. The shifting in $\lambda_{\max }$ and their intensities of bands led to predict the chelating behavior, i.e., coordination occurs through ring carbonyl oxygen atom with the nitrogen atom of azo group. The spectra of metal complexes also show additional bands in (546-563) (w) $\mathrm{cm}^{-1}$ and (480-418) (w) $\mathrm{cm}^{-1}$ which is probably due to the formation of $v(\mathrm{M}-\mathrm{O})$ and $v(\mathrm{M}-\mathrm{N})$ bond respectively. ${ }^{13}$

Table 1 The most important band and their assignments of $\mathrm{H}_{4} \mathrm{~L}$ and their complexes $\left(\mathrm{cm}^{-1}\right)$

\begin{tabular}{|c|c|c|c|c|c|c|c|c|}
\hline Compound & vOH & $\begin{array}{l}\text { vC-H } \\
\text { Aromatic }\end{array}$ & $v \mathbf{C}=\mathbf{O}$ & $v \mathbf{N}=\mathbf{N}$ CNNC & $v \mathrm{CN}=\mathrm{NC}$ & $v(C-N)$ & $v(M-O)$ & $v(M-N)$ \\
\hline $\mathbf{H}_{4} \mathbf{L}$ & $3415.9 \mathrm{~s}$ & $3194.12 \mathrm{~m}$ & $1676.14 \mathrm{~s}$ & $\begin{array}{l}1535.34 \mathrm{~m} \\
1494.8 \mathrm{~s}\end{array}$ & $\begin{array}{l}1109.07 \mathrm{~m} \\
1053.13 \mathrm{~m}\end{array}$ & ----- & ----- & ------ \\
\hline Pd-L & $3417 \mathrm{~s}$ & $3128.04 \mathrm{~m}$ & $1649.19 \mathrm{~s}$ & $\begin{array}{l}1553.5 \mathrm{w} \\
1491.02 \mathrm{~m}\end{array}$ & $\begin{array}{l}1132.25 \mathrm{~s} \\
1111.03 \mathrm{~s}\end{array}$ & $1400 \mathrm{~m}$ & $534.3 w$ & $480 w$ \\
\hline $\mathrm{Ni}-\mathrm{L}$ & $3408.22 \mathrm{~s}$ & $3227.94 w$ & $1627.92 \mathrm{~s}$ & 1496.76w & $\begin{array}{l}1151.5 \mathrm{~m} \\
1118.71 \mathrm{~m}\end{array}$ & $1406.11 \mathrm{~m}$ & $513.07 \mathrm{w}$ & $414.70 \mathrm{w}$ \\
\hline Ag-L & $3423.76 \mathrm{~s}$ & ------ & $1651.12 \mathrm{~s}$ & $\begin{array}{l}1514.17 \mathrm{~m} \\
1383 \mathrm{~s}\end{array}$ & $\begin{array}{l}1136.11 \mathrm{w} \\
1030.02 \mathrm{w}\end{array}$ & ----- & $513.08 \mathrm{w}$ & $450 w$ \\
\hline
\end{tabular}

s, strong; m, medium; w, weak.

Effect of pH: The influence of $\mathrm{pH}$ value on the absorbance of complexes was studied at different $\mathrm{pH}$ (Figure 2) by using of $\mathrm{HCl}$ and $\mathrm{NaOH}(0.05 \mathrm{M})$ solutions $(\mathrm{pH} 2-10)$. It was found that the highest absorbance of $\mathrm{Pd}-\mathrm{L}, \mathrm{Ni}-\mathrm{L}$ and $\mathrm{Ag}-\mathrm{L}$ at $\mathrm{pH} 3,8$ and 6 respectively, because of the formation of the anionic form of the reagent, which can easily react with ions to form complexes.
Effect of reagent volume: Various volume of HL $(0.5-4 \mathrm{ml})$ of $1 \times 10^{-}$ ${ }^{3} \mathrm{M}$ were added to a fixed amount of $\mathrm{Pd}(\mathrm{II}), \mathrm{Ni}(\mathrm{II})$ and $\mathrm{Ag}(\mathrm{I})$ of $10 \mathrm{ppm}$ $(2 \mathrm{ml})$. It's found enough to develop the color to its full intensity and give a minimum blank value and were considered to be optimum for the volume 3, 3 and $2 \mathrm{ml}$ respectively. Figure 3 show the effect of concentration HL with ions. 


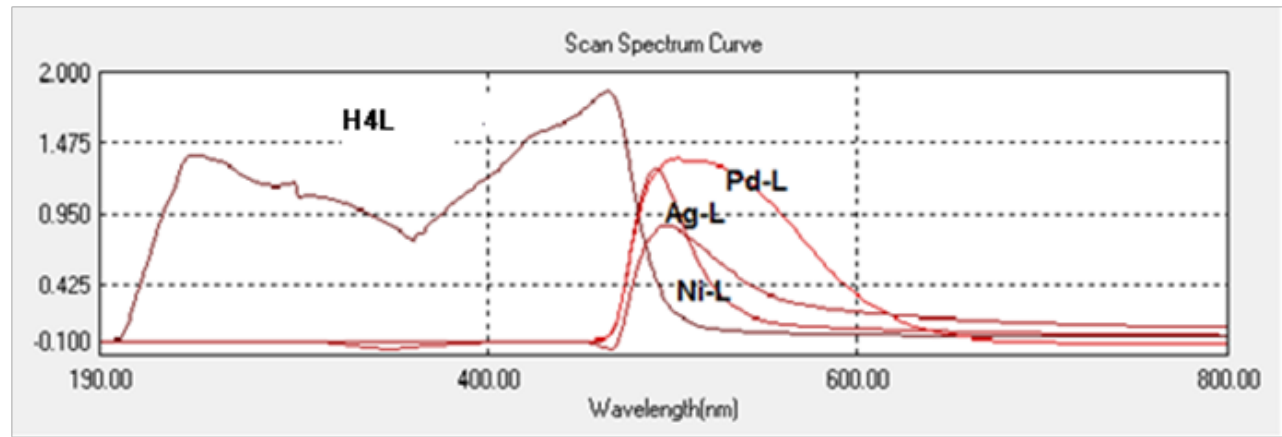

Figure 1 The absorbance $\lambda_{\text {max }}$ of $\mathrm{H}_{4} \mathrm{~L}$ and their complexes.

Table 2 Analytical characteristics of metal-1 complexes

\begin{tabular}{|c|c|c|c|}
\hline Characteristic & Pd(II) & $\mathrm{Ni}(\mathrm{II})$ & $\operatorname{Ag}(\mathbf{I})$ \\
\hline Absorption maxima $\left(\lambda_{\max }\right) \mathrm{nm}$ & 504 & 495 & 492 \\
\hline Bee's law range $(\mu \mathrm{g} / \mathrm{ml})$ & $0.1-3$ & $0.1-3$ & $0.1-3$ \\
\hline Molar absorptivity $\left(\mathrm{L} \cdot \mathrm{mol}^{-1} \mathrm{~cm}^{-1}\right)$ & $3.565 \times 10^{3}$ & $1.966 \times 10^{3}$ & $4.735 \times 10^{3}$ \\
\hline Sandell's sensitivity $\left(\mu \mathrm{gcm}^{2}\right)$ & 0.0298 & 0.0298 & 0.0227 \\
\hline $\mathrm{pH}$ & 3 & 8 & 6 \\
\hline Stability constant & $1.406 \times 10^{10}$ & $2.191 \times 10^{10}$ & $1.2 \times 10^{7}$ \\
\hline
\end{tabular}

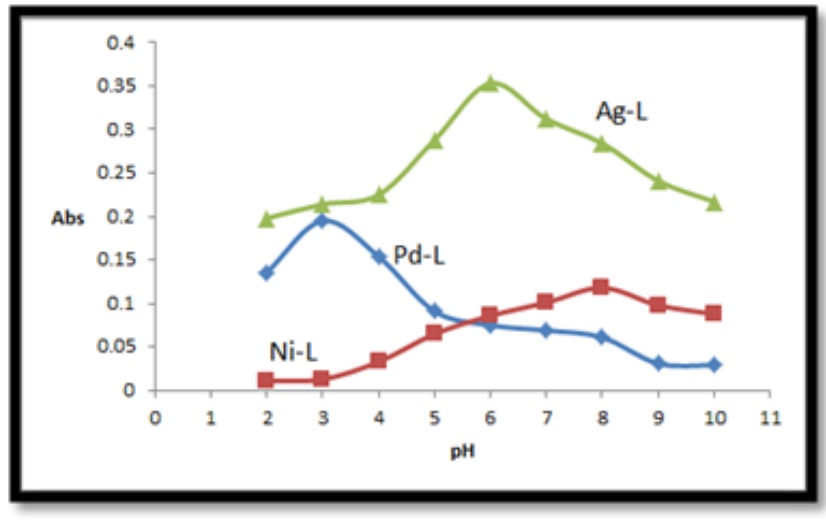

Figure 2 Effect of $\mathrm{pH}$.

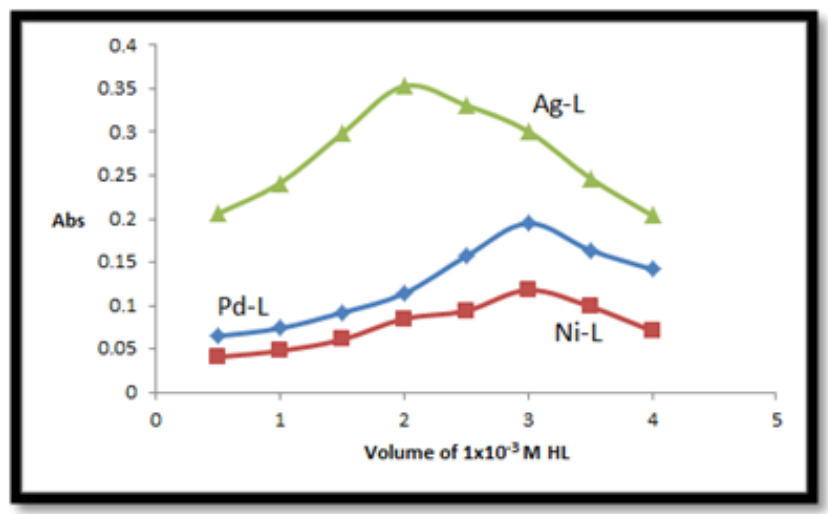

Figure 3 The effect of concentration $\mathrm{HL}$ on $\mathrm{Pd}(\mathrm{II}), \mathrm{Ni}(\mathrm{II})$ and $\mathrm{Ag}(\mathrm{I})$ ions.
Effect of time: The stability of complexes with time was showed in Figure 4, from the data obtained it was found that the highest absorbance reached at $15 \mathrm{~min}$ and remains constant up $24 \mathrm{hrs}$ with respect to Pd-L, Ni-L and Ag-L respectively.

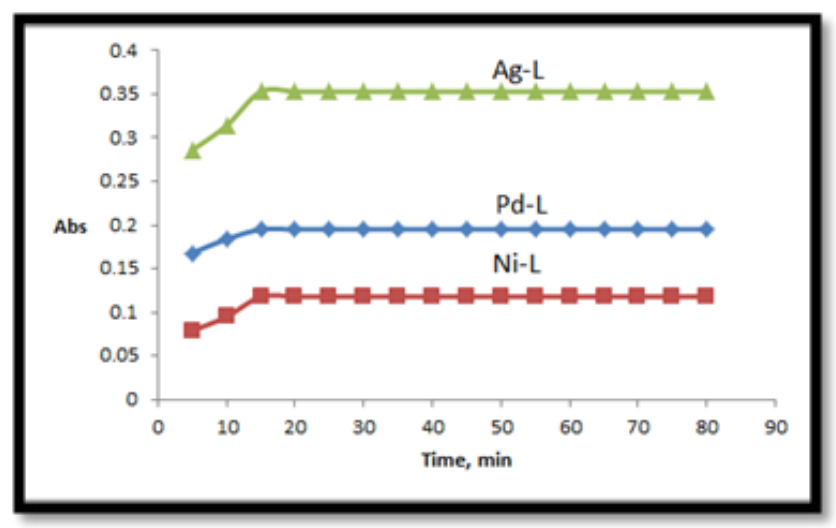

Figure 4 The effect of time.

Calibration graph: At optimum conations, a linear calibration graphs for Pd-L, Ni-L and Ag-L were obtained, (Figure 5-7) that Beers low is obeyed over the concentration range of (0.1-3ppm) Pd(II), Ni(II) and $\operatorname{Ag}(\mathrm{I})$ with $\mathrm{R}^{2}$ equal to (0.9978), (0.9981) and (0.9982) respectively. The results of analytical performance are summarized in Table 3.

Conductivity measurements: The solubility of the complexes in dimethylsulfoxide (DMSO), ethanol and methanol permitted of the molar conductivity of $1 \times 10^{-3} \mathrm{M}$ solution at $25^{\circ} \mathrm{C}$ and by comparison, the electrolytic nature of complexes. The lower values of the molar conductance data listed in Table 3 indicate that the complexes are nonelectrolytes. 


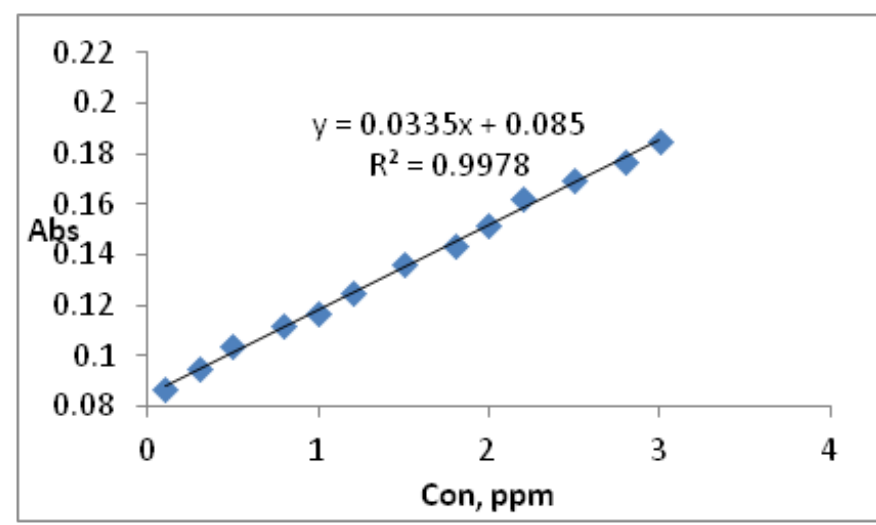

Figure 5 Calibration curve of Pd-L.

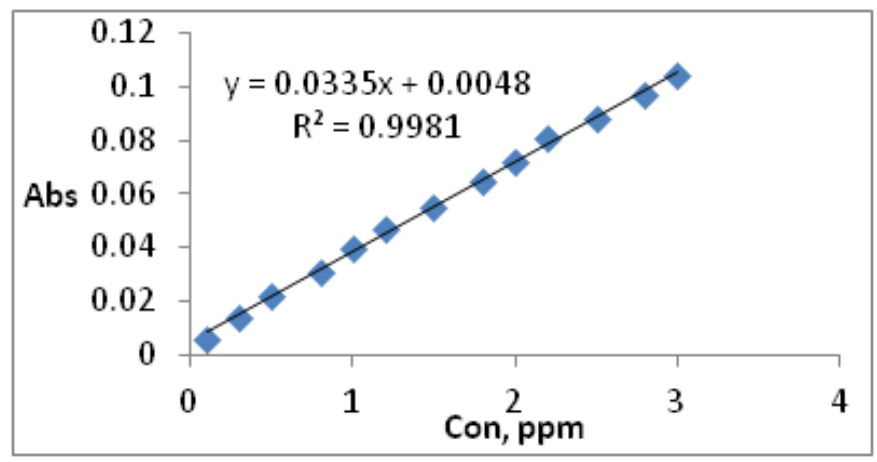

Figure 6 Calibration curve of Ni-L.

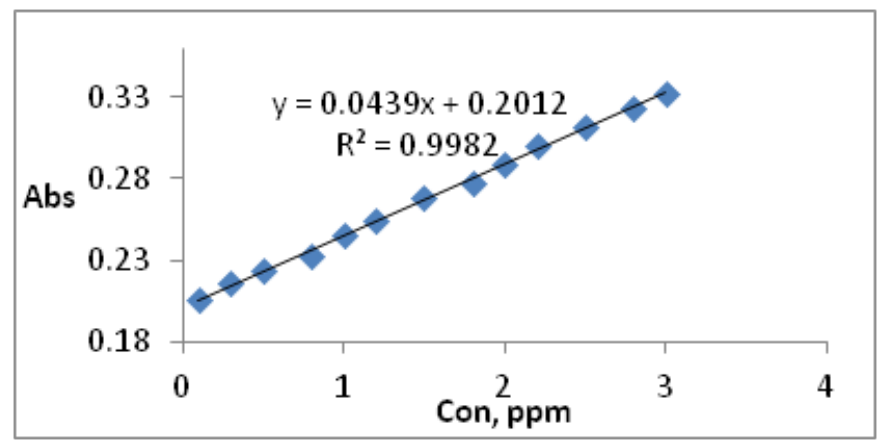

Figure 7 Calibration curve of Ag-L.

\section{Accuracy and precision}

To determine the accuracy and precision of the method, Pd(II), $\mathrm{Ni}(\mathrm{II})$ and $\mathrm{Ag}(\mathrm{I})$ were determined at three different concentrations. The results shown in Table 4 a satisfactory precision and accuracy with the proposed method.

Effect of interferences: The effect of diverse ions as interferences was studied. To test of diverse ions was determined by the general procedure, in the presence of their respective foreign ions. In the experiment, a suitable amount of the standard ions solution, coexisting ion solution and masking agent were added. The metal ions can be determined in thepresence of a 10 fold excess of cation and anion, the results are listed in Table 4. They found that large amounts of $\mathrm{NO}_{3}^{-1}, \mathrm{Cl}^{-1}, \mathrm{CO}_{3}^{-2}$ and $\mathrm{SO}_{4}^{-2}$ have a few effects of ions. It's found that positive ions interfere seriously and can make the absorbance increase or decrease. However, their interferences are masked efficiently by the addition of $(0.5-2.0 \mathrm{ml})$ of $0.1 \mathrm{M}$ of sodium nitrate for palladium and nickel and $(0.5-1.5 \mathrm{ml})$ of $0.1 \mathrm{M}$ of oxalic acid for silver.

Composition of the complexes (stoichiometery): The empirical formula of the complexes was evaluated by using a continuous variation method (Jop's method) and Mole Ratio Method..$^{14}$ It was found that complexes form 1:2 for Pd (II) and $\mathrm{Ni}(\mathrm{II})$ but 1:1 for $\mathrm{Ag}(\mathrm{I})$ (M:L), (Figure 8-13) show the Composition of the complexes. On the basic of the FTIR, stoichiomstric and conductivity data, the structures of complexes can be suggested as the following (Figure $14 \&$ Figure $15)$.

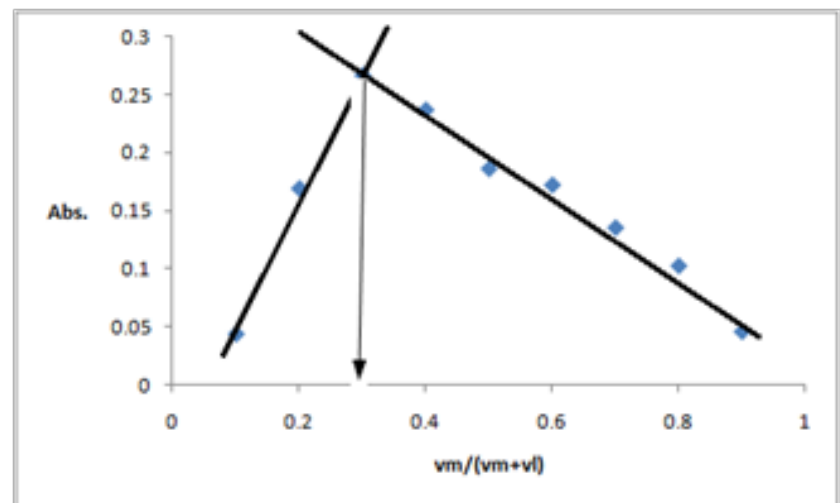

Figure 8 Job's method of the Pd-L.

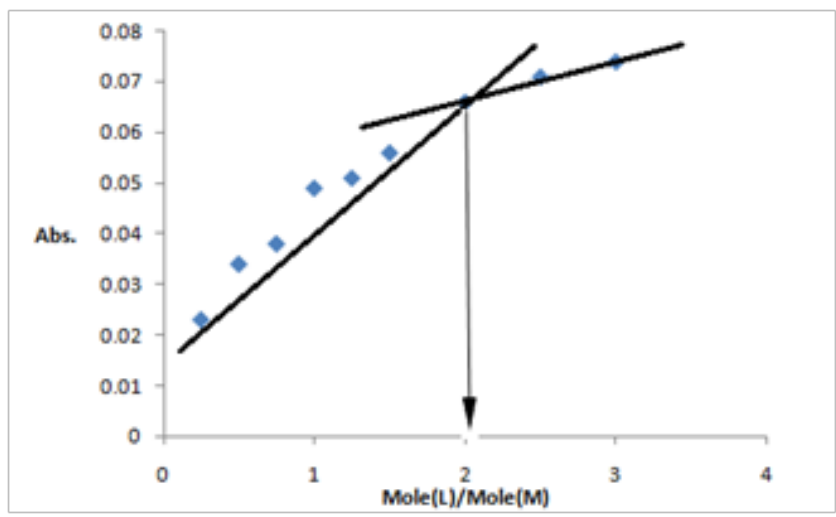

Figure 9 Mole ratio of the Pd-L.

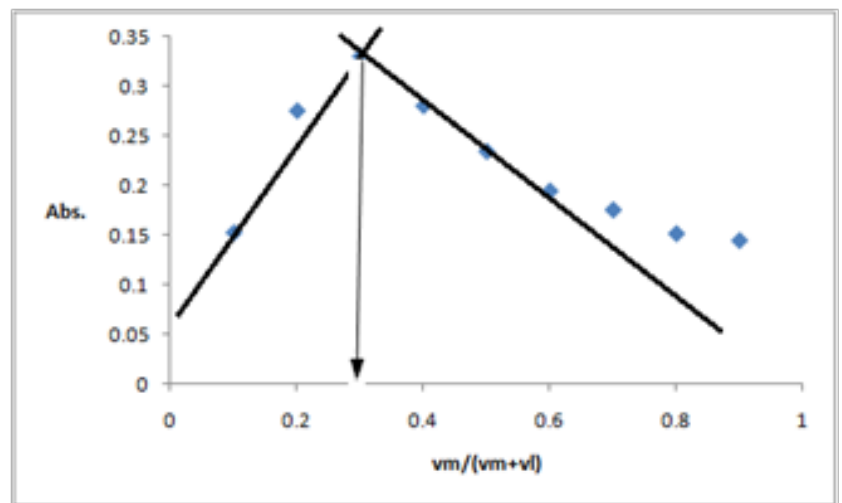

Figure 10 Job's method of the Ni-L.

Thermal analysis: TG/HDSC analyses are very useful methods for investigating the thermal decomposition of solid substances involving simple metal salts as well as for complex compounds. ${ }^{15,16}$ The thermogram follows the decrease in sample weight with the linear 
increase in heat treatment temperature $\left(10^{\circ} \mathrm{C} \mathrm{min}^{-1}\right)$ up to $400^{\circ} \mathrm{C}$. The decomposition occurs in at least three major detectable steps, each step does not refer in generally to single process, but rather is reflects of two or three overlapping processes and attributed to the ligand alone or companied by chlorine atoms. The aim of the thermal analysis is to obtain information concerning the thermal stability of the investigated complexes as seen in Table 5 and (Figure 16-19), to decide whether water molecules are inside or outside the coordination sphere. All the complexes show three-stage mass loss in their TG/HDSC curves.

Table 3 Conductivity values of complexes

\begin{tabular}{|c|c|c|c|}
\hline Complexes & $\begin{array}{l}\text { Molar conductivity } \mathrm{S} \mathrm{mol}^{-1} \mathrm{~cm}^{2} \\
\text { DMSO }\end{array}$ & $\begin{array}{l}\text { Molar conductivity } S \mathrm{~mol}^{-1} \mathrm{~cm}^{2} \\
\text { Ethanol }\end{array}$ & $\begin{array}{l}\text { Molar conductivity S mol-1 } \mathrm{cm}^{2} \\
\text { Methanol }\end{array}$ \\
\hline Pd-L & 9.6 & 11.2 & 13.4 \\
\hline Ni-L & 7.3 & 8.7 & 11.8 \\
\hline Ag-L & 10.9 & 12.6 & 14.5 \\
\hline
\end{tabular}

Table 4 Accuracy and precision values of complexes

\begin{tabular}{llllll}
\hline Ion & Con. ppm & \%R.S.D & \%Error & D.L & \%Recovery \\
\hline \multirow{2}{*}{$\operatorname{Pd}(\mathrm{II})$} & 0.1 & 0.93136 & 0.7604 & 0.00279 & 99.2395 \\
& 0.5 & 0.93786 & 0.79491 & 0.01406 & 99.2050 \\
$\mathrm{Ni}(\mathrm{II})$ & 1.0 & 0.96817 & 0.39525 & 0.02904 & 99.6047 \\
& 1.5 & 0.93324 & 0.60240 & 0.04199 & 99.3975 \\
$\mathrm{Ag}(\mathrm{I})$ & 0.1 & 0.94143 & 0.16155 & 0.002374 & 99.8384 \\
& 0.5 & 0.96153 & 0.29673 & 0.014423 & 99.703 \\
\hline
\end{tabular}

*for six determinations

Table 5 Effect of foreign ions

\begin{tabular}{|c|c|c|c|c|c|}
\hline Foreign Ions & Formula & Amount added $\mu \mathrm{g} / \mathrm{ml}$ & $\begin{array}{l}\text { Interferences } \\
\text { with Pd }\end{array}$ & $\begin{array}{l}\text { Interferences } \\
\text { with } \mathrm{Ni}\end{array}$ & $\begin{array}{l}\text { Interferences } \\
\text { with } \mathrm{Ag}\end{array}$ \\
\hline $\mathrm{Cu}^{2+}$ & $\mathrm{CuCl}_{2} \cdot 2 \mathrm{H}_{2} \mathrm{O}$ & 100 & 6.66 & 4.23 & 10.48 \\
\hline $\mathrm{Pb}^{2+}$ & $\mathrm{PdCl}_{2}$ & 100 & -1.02 & -2.54 & -1.19 \\
\hline $\mathrm{Co}^{2+}$ & $\mathrm{CoCl}_{2} \cdot 6 \mathrm{H}_{2} \mathrm{O}$ & 100 & 1.53 & 5.93 & 17.56 \\
\hline $\mathrm{Fe}^{3+}$ & $\mathrm{FeCl}_{3}$ & 100 & 8.2 & 10.16 & 16.14 \\
\hline $\mathrm{Mn}^{2+}$ & $\mathrm{MnCl}_{2}$ & 100 & 12.3 & 22.88 & -2.26 \\
\hline $\mathrm{Hg}^{2+}$ & $\mathrm{HgCl}_{2}$ & 100 & 58.97 & 14.4 & -7.93 \\
\hline $\mathrm{V}^{5+}$ & $\mathrm{NH}_{4} \mathrm{VO}_{3}$ & 100 & 10.25 & 19.49 & 18.9 \\
\hline $\mathrm{Cl}^{-}$ & $\mathrm{KCl}$ & 100 & 1.33 & 1.07 & -2.6 \\
\hline $\mathrm{CO}_{3}{ }^{2-}$ & $\mathrm{Na}_{2} \mathrm{CO}_{3}$ & 100 & 1.02 & 2.37 & 4. 89- \\
\hline $\mathrm{Br}$ & $\mathrm{NaBr}$ & 100 & -1.5 & 1.93 & 3.14 \\
\hline $\mathrm{SO}^{2-}$ & $\mathrm{Na}_{2} \mathrm{SO}_{4}$ & 100 & -1.32 & 1.62 & 1.41 \\
\hline $\mathrm{I}^{-}$ & $\mathrm{KI}$ & 100 & -0.79 & -1.23 & -1.39 \\
\hline
\end{tabular}

For $\mathrm{H}_{4} \mathrm{~L} \mathrm{C}_{25} \mathrm{H}_{16} \mathrm{~N}_{4} \mathrm{O}_{9}$ from the TG curve, it appears that the sample decomposes in two stages. The first stage decomposition occurs at $207.1^{\circ} \mathrm{C}$ with a mass loss of $2.0 \%$ and the second decomposition at $352.8^{\circ} \mathrm{C}$ with a $48 \%$ mass loss. For palladium complexes $\left(\mathrm{C}_{50} \mathrm{H}_{34} \mathrm{~N}_{8} \mathrm{O}_{18} \mathrm{Pd}\right)$, the data obtained support the proposed structure and indicate that $\mathrm{Pd}(\mathrm{II})$ complex undergo three step degradation reaction. The first step occurs at maximum peak lying in $85.6^{\circ} \mathrm{C}$, corresponding to the loss of $2 \%$ the weight loss associated with this step agrees quite well with the loss one terminal methyl groups in 4-aminoantipyrine moiety. The second step occurs at $\mathrm{T}_{\max } 150.7^{\circ} \mathrm{C}$, corresponding to the loss of $3 \%$ and it referred to loss of chlorine atom. The third decomposition step occurs at $\mathrm{T}_{\max } 354.6^{\circ} \mathrm{C}$ corresponding to the loss of $25 \%$ referred to a single process, but it's reflective of two or three overlapping processes and attributed to loss of the 4-aminoantipyrine and moieties. The residual is in agreement with Pd metal. For Ni complex $\left(\mathrm{C}_{50} \mathrm{H}_{34} \mathrm{~N}_{8} \mathrm{NiO}_{18}\right)$, the data obtained support the proposed structure and indicate that $\mathrm{Ni}$ (II) complex undergo three step degradation reaction. The first step occurs at maximum peak lying in $157.7^{\circ} \mathrm{C}$, corresponding to the loss of $2 \%$ the weight loss associated with this step agrees quite well with the loss of one water molecule. The second step occurs at $\mathrm{T}_{\max } 189.2^{\circ} \mathrm{C}$, corresponding to the loss of $6 \%$ and it referred to loss two terminal methyl groups in 4-aminoantipyrine moiety The third decomposition step occurs at $\mathrm{T}_{\max }\left(358.3^{\circ} \mathrm{C}\right)$ corresponding to the loss of $35 \%$ referred to a single 
process, but it's reflective of two or three overlapping processes and attributed to loss of the 4- aminoantipyrine and moieties. For Ag complex $\left(\mathrm{C}_{25} \mathrm{H}_{16} \mathrm{AgN}_{5} \mathrm{O}_{12}\right)$, a mass loss occurred within the temperature $115.6^{\circ} \mathrm{C}$ corresponding to the loss of $1 \%$ for one molecule of water the temperature $179.7^{\circ} \mathrm{C}$ a loss of $5.33 \%$, corresponding to a loss of one $\mathrm{NO}_{3}$ molecule at the end of the thermogram at higher temperature $356.3^{\circ} \mathrm{C} . .^{17}$

Table 6 Thermal Analysis

\begin{tabular}{|c|c|c|c|c|c|c|c|c|c|}
\hline \multirow[b]{2}{*}{ Compound } & \multicolumn{3}{|l|}{ First stage } & \multicolumn{3}{|l|}{ Second stage } & \multicolumn{3}{|l|}{ Third stage } \\
\hline & Temperature ${ }^{0} \mathrm{C}$ & M. wt & $\begin{array}{l}\text { Weight } \\
\text { loss } \%\end{array}$ & Temperature ${ }^{0} \mathrm{C}$ & M. wt & $\begin{array}{l}\text { Weight } \\
\text { loss } \%\end{array}$ & Temperature ${ }^{0} \mathrm{C}$ & M. wt & $\begin{array}{l}\text { Weight } \\
\text { loss \% }\end{array}$ \\
\hline$\left(\mathrm{C}_{25} \mathrm{H}_{16} \mathrm{~N}_{4} \mathrm{O}_{9}\right)_{2} \mathrm{Pd}$ & 85.6 & 1126.08 & 2 & 150.7 & 1110.865 & 3 & 354.6 & 852.17 & 25 \\
\hline$\left(\mathrm{C}_{25} \mathrm{H}_{16} \mathrm{~N}_{4} \mathrm{O}_{9}\right)_{2} \mathrm{Ni}$ & 157.7 & 1169.63 & 2 & 189.2 & 1121.89 & 6 & 358.3 & 771.796 & 35 \\
\hline$\left(\mathrm{C}_{25} \mathrm{H}_{16} \mathrm{~N}_{5} \mathrm{O}_{12}\right) \mathrm{Ag}$ & 115.6 & 681.726 & 1 & 179.7 & 649.697 & 5.33 & 356.3 & 466.684 & 32 \\
\hline
\end{tabular}

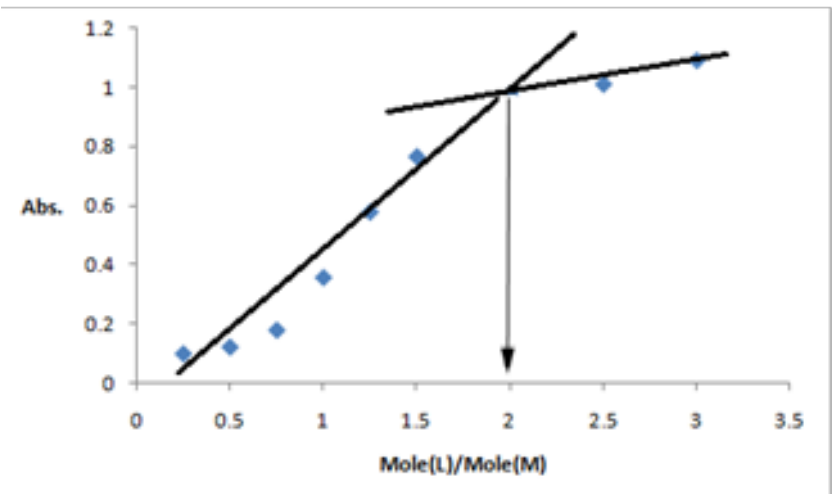

Figure 11 Mole ratio of the Ni-L.

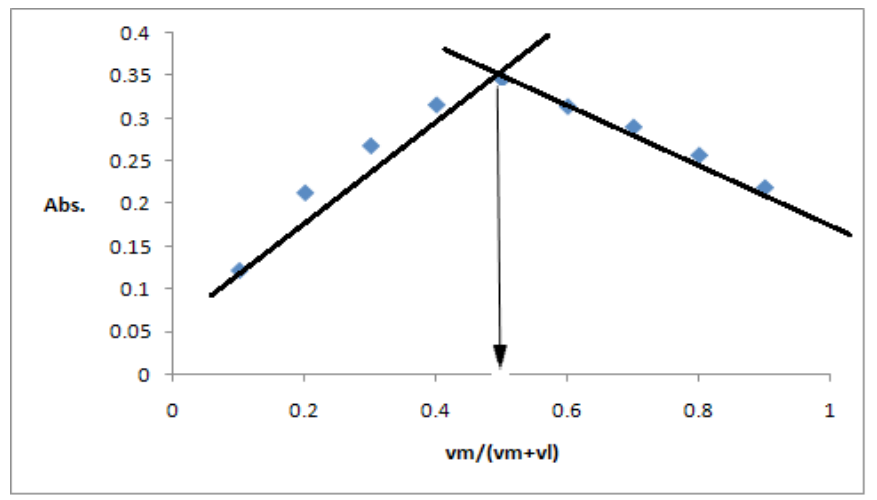

Figure 12 Job's method of the Ag-L.

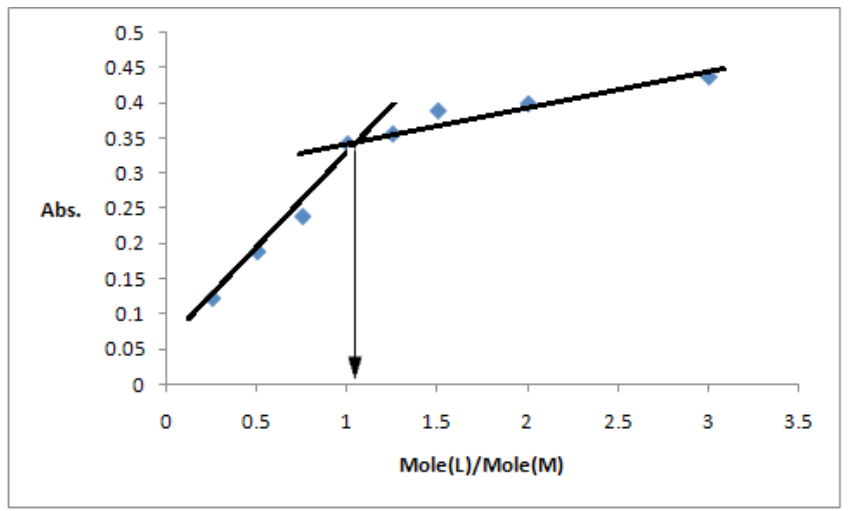

Figure 13 Mole ratio of the Ag-L.

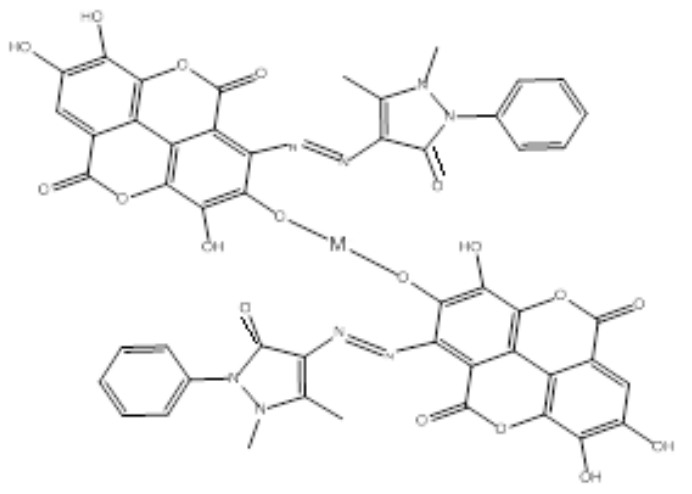

Figure14 The proposed structural formula of metal complexes ( $\mathrm{M}=\mathrm{Pd}(\mathrm{II})$ and $\mathrm{Ni}(\mathrm{II}))$.

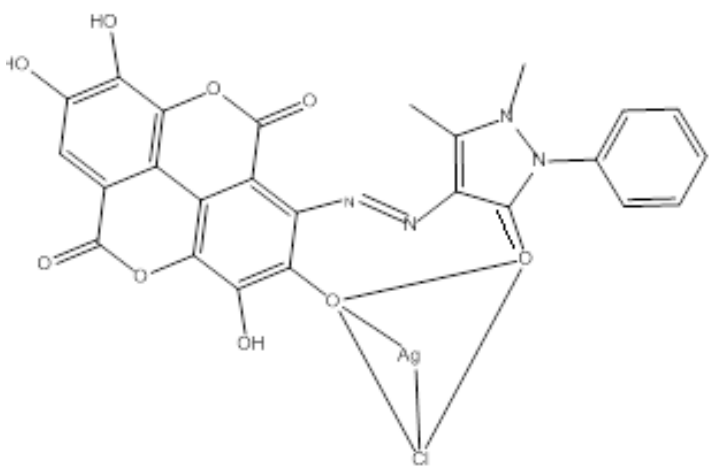

Figure 15 The proposed structural formula of Ag metal complex.

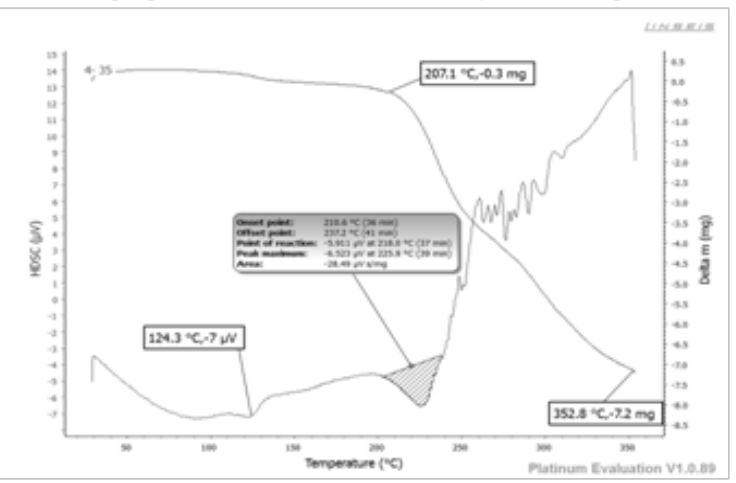

Figure 16 TG/HDSC thermogram of HL. 


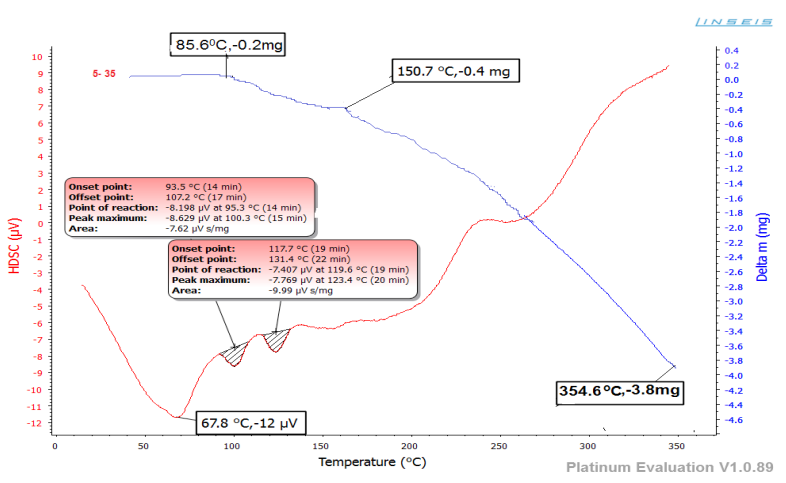

Figure 17 TG/HDSC thermogram of Pd-L.

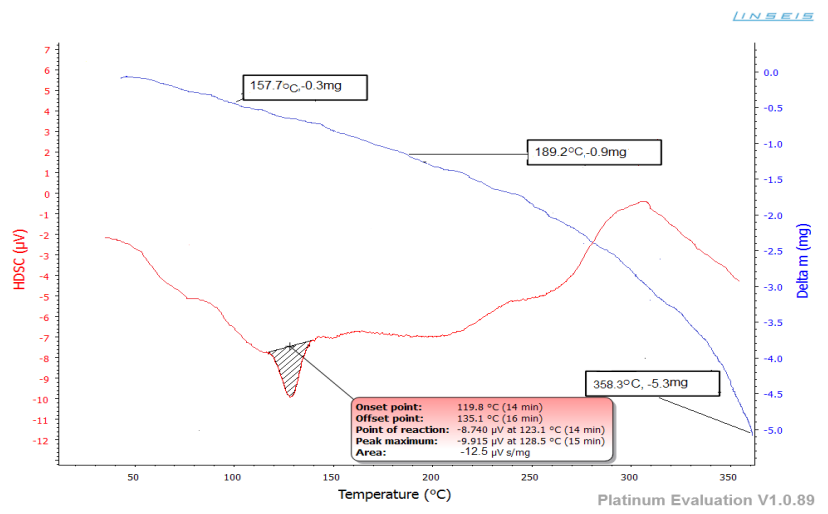

Figure 18 TG/HDSC thermogram of Ni-L.

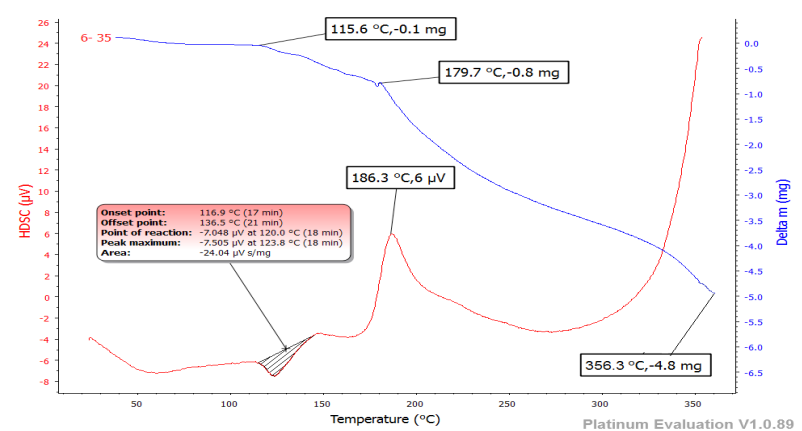

Figure 19 TG/HDSC thermogram of Ag-L.

\section{Applications}

To determination of ions determined according to the spectrophotometric method and atomic absorption in Al-Kufa and AlKfel rivers, we use the following methods. ${ }^{18}$ For Pd(II): $500 \mathrm{ml}$ of water sample was concentrated to about $10 \mathrm{ml}$ by heating on a hot plate. $10 \mathrm{ml}$ of nitric acid and $5 \mathrm{ml}$ of $30 \%$ hydrogen peroxide were added in this solution. The mixture was heated on a hot plate and evaporated to near dryness. The residue was dissolved in $10 \mathrm{ml}$ of $10 \% \mathrm{HCl}$ and transferred into a calibrated flask (100ml).For Ni(II):The water sample $(500 \mathrm{ml})$ was collected in a clean container and evaporated to about $25 \mathrm{ml}$. Then $5 \mathrm{ml}$ of $\mathrm{H}_{2} \mathrm{O}_{2}$ was added and evaporated to dryness. It was then dissolved in $20 \mathrm{ml}$ of water and filtered to remove insoluble substances. The filtered was collected in $100 \mathrm{ml}$ volumetric flask quantitatively to the mark with distilled water. For $\operatorname{Ag}(\mathrm{I})$ : The water was filtered through filter paper no. 41 . The $\mathrm{pH}$ of filtered sample was adjusted to 2 with 1:1 nitric acid solution. The results obtained are given in Table 7.

Table 7 Determination of $\mathrm{Pd}(\mathrm{II}) \mathrm{Ni}(\mathrm{II})$ and $\mathrm{Ag}(\mathrm{I})$ in water

\begin{tabular}{|c|c|c|c|c|c|c|}
\hline \multirow{2}{*}{ Samples } & \multicolumn{2}{|l|}{$\operatorname{Pd}($ II) } & \multicolumn{2}{|l|}{$\mathrm{Ni}(\mathrm{II})$} & \multicolumn{2}{|l|}{$\operatorname{Ag}(\mathbf{I})$} \\
\hline & $\begin{array}{l}\text { atomic absorption } \\
\mu \mathrm{g} \cdot \mathrm{ml}^{-1}\end{array}$ & $\begin{array}{l}\text { Spectro. } \\
\text { method ppm }\end{array}$ & $\begin{array}{l}\text { atomic absorption } \\
\mu \mathrm{g} \cdot \mathrm{ml}^{-1}\end{array}$ & $\begin{array}{l}\text { Spectro. method } \\
\text { ppm }\end{array}$ & $\begin{array}{l}\text { atomic absorption } \\
\mu \mathrm{g} \cdot \mathrm{ml}^{-1}\end{array}$ & Spectro. method ppm \\
\hline Al-Kufa & 0.0156 & 0.0158 & 0.0479 & 0.0477 & 0.0146 & 0.0145 \\
\hline Al-Kfel rivers & 0.0027 & 0.0025 & 0.0403 & 0.0401 & 0.0075 & 0.0074 \\
\hline
\end{tabular}

\section{Acknowledgements}

None.

\section{Conflict of interest}

The author declares that there is no conflict of interest.

\section{References}

1. Alaghaz AMA, Zayed ME, Alharbi SA. Synthesis, spectral characterization, molecular modeling and antimicrobial studies of tridentate azo-dye Schiff base metal complexes. Journal of Molecular Structure. 2015;1084:36-45.

2. ElGhamaz NA, ElSonbati AZ, Diab MA, et al. Thermal, dielectrical properties and conduction mechanism of $\mathrm{Cu}(\mathrm{II})$ complexes of azo rhodanine derivatives. Materials Research Bulletin. 2015;65:293-301.

3. Sen C, Roy S, Mondal TK, et al. Palladium(II)-iodo-\{1-alkyl-2(arylazo)imidazole\} complexes: Synthesis, structure, dynamics of photochromism and DFT computation. Polyhedron.2015;85:900-911.
4. Kurdekar GS, Sathish MP, Budagumpi S, et al. 4-Aminoantipyrinebased Schiff-base transition metal complexes as potent anticonvulsant agents. Medicinal Chemistry Research.2011;21:2273-2279.

5. Al-Hamdani AAS, Zoubi WA1. New metal complexes of N3 tridentate ligand: Synthesis, spectral studies and biological activity, Spectrochimica Acta Part A. Molecular and Biomolecular Spectroscopy. 2015;137:7589.

6. Gaber M, ElSayed YS, ElBaradie K, et al. Cu(II) complexes of monobasic bi or tridentate (NO, NNO) azo dye ligands: Synthesis, characterization, and interaction with Cu-nanoparticles, Journal of Molecular Structure. 2013;1032:185-194.

7. Chequer FMD, deOliveira GAR, Ferraz ERA, et al. Textile dyes: dyeing process and environmental impact. In: Gunay M (ed) Eco-friendly textile dyeing and finishing. InTech Press. 2013.

8. Joseph J, Rani BAG. Metal based SOD mimetic therapeutic agents: Synthesis, characterization and biochemical studies of metal complexes. Arabian Journal of Chemistry. 2017;10(suppl 2):1963-1972. 
9. Figueroa JB, Ochoa SH, Barragán AP, et al. Continuous production of ellagic acid in a packed-bed reactor. Process Biochemistry. 2014;49(issue 10):1595-1600

10. Tang J, Liang G, Zheng C, et al. Investigation on the Binding Behavior of Ellagic Acid to Human Serum Albumin in Aqueous Solution. Journal of Solution Chemistry. 2013;42(issue 1):226-238.

11. Fadd AA, Elattar KM. Synthesis of Novel Azo Disperse dyes Derived from 4-Aminoantipyrine and their Applications to Polyester Fabrics. American Journal of Organic Chemistry. 2012;2(issue 3):52-57.

12. Singh A, Choi R, Choi B. Synthesis and properties of some novel pyrazolone-based heterocyclic azo disperse dyes containing a fluorosulfonyl grou.Dyes and Pigments. 2012;95:580-586.

13. AlSaif FA. Spectroscopic Elucidation, Conductivity and Activation Thermodynamic Parameters Studies on Pt(IV), Au(III) and $\mathrm{Pd}(\mathrm{II})$ 1,5-Dimethyl-2-phenyl-4-[(thiophen-2-ylmethylene)-amino]-1,2dihydro-pyrazol-3-one Schiff Base Complexes. Int J Electrochem. Sci. 2013;9:398-417.

14. Malik AK, Kaul KN, Lark BS. Spectrophotometric Determination of Cobalt, Nickel, Palladium, Copper, Ruthenium and Molybdenum Using
Sodium Isoamylxanthate in Presence of Surfactants. Turk $J$ Chem. 2001;25:99-105.

15. Merdivan M, Karipcin Kulcu F, Aygun RS. Study of the Thermal Decompositions on N,N-Dialkyl-N'-ben zoylthiourea Complexes OF $\mathrm{Cu}(\mathrm{II}), \mathrm{Ni}(\mathrm{II}), \mathrm{Pd}(\mathrm{II}), \mathrm{Pt}(\mathrm{II}), \mathrm{Cd}(\mathrm{II}), \mathrm{Ru}(\mathrm{III})$ AND Fe(III). Journal of Thermal Analysis and Calorimetry.2012;58:551-557.

16. Arshad M, Rehman S, Qureshi AH, et al. Thermal Decomposition of Metal Complexes of Type MLX2 (M = Co(II), Cu(II), Zn(II), and Cd(II); $\mathrm{L}=\mathrm{DIE} ; \mathrm{X}=\mathrm{NO} 31-)$ by TG-DTA-DTG Techniquesin Air Atmosphere. Turk J Chem. 2008;32:593-604.

17. Marandia F, Marandib A, Pantenburgc I, et al. Synthesis and Spectroscopic, Thermal and Electrochemical Studies of Mixed-ligand Complexes of Silver(I) with Derivatives of Benzoyltrifluoroacetonate and 4,40-Bipyridine, Including the Crystal Structure of $[\operatorname{Ag}(4,40$-bpy) (tfcpb)]n. Z Naturforsch. 2012;67b:465-472.

18. Balcerzak M. Sample Digestion Methods for the Determination of Traces of Precious Metals by Spectrometric Techniques. Anal Sci. 2002; 18(issue 7): 737-750. 